\title{
Profile of typhoid fever in admitted pediatric patients from tertiary care hospital
}

\author{
Desai $\mathbf{P}^{1}$, Vijapura A. $\mathbf{Y}^{2}$ \\ ${ }^{1}$ Dr Pankti Desai, Assistant Professor, ${ }^{2}$ Dr Abidali Y Vijapura, Associate Professor, AMC MET Medical College, \\ Ahmedabad, Gujarat, India
}

Address for Correspondence: Dr Pankti Desai, 7 Yashnirman Flats, Bhagatbaug Society, New Shardamandir Road, Paldi, Ahmedabad, E mail id: drpanktidesai@ yahoo.in

\begin{abstract}
Introduction: Typhoid fever is preventable infectious diseases caused by gram negative bacteria Salmonella typhi and is still a major public health problem in India. Objective: The main aim of our study was to find out the clinical profile in admitted pediatric patients of typhoid fever. Design: Retrospective case study .Subjects: 292 hospitalized Widal positive typhoid fever pediatric cases admitted to tertiary care hospital from $1^{\text {st }}$ August 2014 to $31^{\text {st }}$ July 2015 . Methods: Records of all the patients who were discharged with the diagnosis of Widal Positive enteric fever were retrieved, compiled and analyzed. Results: Out of 292 total patients: 18(6.16\%) were below 2 years of age; 54(18.49\%) cases were between 2-5 years; 124(42.46\%) were between 5 to 10 years of age and $96(32.87 \%)$ were above 10 years of age. Fever was the main presenting complains in all cases. Vomiting (49.31\%), diarrhea (36.98\%) and cough (33.56) were common associated complains. Almost all $(289,98.97 \%)$ patients were treated with Injection ceftriaxone after positive Widal reports to start with. Only in 62(21.23\%) patients, oral Azithromycin was added along with ceftriaxone. 58.20\% patients required more than 6 days hospital stay. Conclusion: The incidence of typhoid fever was $5.63 \%$ amongst the total admitted patients. Typhoid fever is having high morbidity but with availability of third generation cephalosporin, mortality has reduced. $24.65 \%$ patients were below 5 years of age which shows changing trends in age of presentation which was considered rare below 5 years of age.
\end{abstract}

Keywords: Typhoid Fever, children, Antibiotics, Widal test

\section{Introduction}

Typhoid fever is one of the most important diseases caused by Salmonella typhi. It is an acute systemic febrile illness. It is manifested by step wise increasing high grade fever, lethargy, headache, vomiting, abdominal pain, hepatosplenomegaly and rarely stupor. The clinical features of the disease in children are nonspecific and vary significantly. It is one of the most important public health problems in India. [1] and carries a significant morbidity and mortality in both pediatric and adult population [ 2 ]. Deffervescence in typhoid fever usually requires at least 36 hours of therapy and fever can persist for 5 to 7 days even with effective therapy [3]. WHO bulletin had mentioned high incidence of enteric fever in below 5 years of age in India, Indonesia and Pakistan [4]. The aim of our study was to find out the disease burden, clinical profile, the Manuscript received: $3^{\text {rd }}$ Oct 2015 Reviewed: $10^{\text {th }}$ Oct 2015 Author Corrected; $19^{\text {th }}$ Oct 201 Accepted for Publication: $4^{\text {th }}$ Nov 2015 age distribution and commonly used effective treatment in admitted patients of typhoid fever in a tertiary care hospital of Ahmedabad. An increase in the incidence of typhoid fever in young children has been reported in many studies $[5,6,7]$. Vi polysaccharide vaccines are given after two years of age but conjugate vaccines can be given in infants also. Study was done and published for effective dissemination of research results for immunization policy.

\section{Material and Methods}

This is a retrospective observational study conducted at Pediatric Department of tertiary care hospital of Ahmedabad. All 292 hospitalized Widal positive typhoid fever pediatric cases ( less than 15 years) admitted during 1 year period from $1^{\text {st }}$ August 2014 to $31^{\text {st }}$ July 2015 were included in the study. 
Case definition: The cases were diagnosed as having typhoid fever if presented with fever (temp >37.5C) for at least 5 days and serum Widal test positive (O titer $>1: 160$ or $\mathrm{H}$ titer $>1: 160)$ [ 8 ].

As most of patients were admitted after 1 week of fever and culture tests were costly, we have used tube agglutination (Widal) test against $\mathrm{O}$ and $\mathrm{H}$ antigen for the diagnosis of typhoid fever which is having sufficient sensitivity and specificity along with cost effectiveness.

All the patients were treated with injectable ceftriaxone to start with. Oral Azithromycin was added when patient remained febrile after five days of injectable ceftriaxone.

\section{Results}

Total 292 hospitalized pediatric patients were diagnosed as having Widal positive typhoid fever from $1^{\text {st }}$ Aug 2014 to $31^{\text {st }}$ July 2015 in Pediatric wards of a tertiary care hospital in Ahmadabad city.

Table 1: Age and Sex distribution of typhoid fever

\begin{tabular}{|c|c|c|c|}
\hline $\begin{array}{c}\text { Age } \\
\text { (in years })\end{array}$ & Total Patients & $\begin{array}{c}\text { Males } \\
\mathbf{n = 1 5 2}\end{array}$ & $\begin{array}{c}\text { Females } \\
\mathbf{n = 1 4 0}\end{array}$ \\
\hline$<2$ & $18(6.16 \%)$ & 11 & 25 \\
\hline $2-5$ & $54(18.49 \%)$ & 29 & 57 \\
\hline $5-10$ & $124(42.46 \%)$ & 67 & 51 \\
\hline $10-15$ & $96(32.87 \%)$ & 45 & \\
\hline
\end{tabular}

Out of 292 total patients: $18(6.16 \%)$ were below 2 years of age; 54(18.49\%) cases were between 2-5 years; 124(42.46\%) were between 5 to 10 years of age and 96(32.87\%) were above 10 years of age. Out of total 292 cases $152(52.05 \%)$ were males and $140(47.94 \%)$ were females.

Table 2: Age Distribution in below 2 years cases

\begin{tabular}{|c|c|}
\hline Age & No of patients (n=18) \\
\hline $0-6$ months & $0(0 \%)$ \\
\hline $6-12$ months & $2(11.11 \%)$ \\
\hline $12-18$ months & $7(38.88 \%)$ \\
\hline $18-24$ months & $9(50 \%)$ \\
\hline
\end{tabular}

Out of $6.16 \%(n=18)$ cases who were below 2 years of age; most of them were above 1 year $(88.88 \%)$ and only $11.11 \%$ were between 6 months to 12 months. No case was reported below 6 months. 
Table 3: Clinical Features of typhoid fever

\begin{tabular}{|l|c|c|}
\hline Clinical features & No of patients & $\%$ \\
\hline Fever & 292 & $100 \%$ \\
\hline Vomiting & 144 & $49.31 \%$ \\
\hline Diarrhea & 108 & $36.98 \%$ \\
\hline $\begin{array}{l}\text { Anorexia, malaise, bodyache } \\
\text { And headache }\end{array}$ & 124 & $42.46 \%$ \\
\hline Cough & 98 & $33.56 \%$ \\
\hline Altered sensorium & 8 & $2.73 \%$ \\
\hline Convulsion & 6 & $2.05 \%$ \\
\hline Hepatomegaly & 210 & $71.91 \%$ \\
\hline Splenomegaly & 103 & $35.27 \%$ \\
\hline Coated Tongue & 42 & $14.38 \%$ \\
\hline
\end{tabular}

Fever was the main presenting complains in all cases. Vomiting was present in 144(49.31\%) cases and diarrhea in $108(36.98 \%)$ cases along with fever. $98(33.56 \%)$ complained of cough and $124(42.46 \%)$ cases complained of malaise, anorexia, body ache, headache etc. vague complains. Altered sensorium in form of delirium was noted in $8(2.73 \%)$ cases and convulsions were present in $6(2.05 \%)$ cases mostly with fever episode (febrile seizures).Hepatomegaly 150 $(51.36 \%)$, Splenomegaly $43(14.72 \%)$ or both hepatosplenomegaly $60(20.54 \%)$ were noted in total $253(86.64 \%)$ cases. Coated tongue was noticed in $42(14.38 \%)$ cases.

Table 4: Diagnostic tests done for typhoid

\begin{tabular}{|c|c|c|}
\hline Diagnostic Tests & Done & Positive \\
\hline Serum Widal & 292 & $292(100 \%)$ \\
\hline Blood Culture & 15 & $4(26.66 \%)$ \\
\hline Stool Culture & 3 & $2(66.66 \%)$ \\
\hline
\end{tabular}

All patients were diagnosed as having typhoid after Widal test (Tube Agglutination Test) positive (O titer or $\mathrm{H}$ titer $>1: 160$ ). Blood Culture was sent in only 15 patients out of which only 4 samples turned out to be positive for Salmonella typhi. Stool cultures were sent in 3 patients with prolonged fever and diarrhea, of which two samples turned out positive for Salmonella typhi.

Table 5: Antibiotics used in Enteric Fever

\begin{tabular}{|c|c|c|}
\hline Antibiotics Given & No of cases & \% \\
\hline Inj.Ceftraixone alone & 227 & $77.73 \%$ \\
\hline $\begin{array}{c}\text { Inj.Ceftriaxone+oral azithromycin } \\
\text { for 5 days }\end{array}$ & 62 & $21.23 \%$ \\
\hline Other drugs & 3 & $1.02 \%$ \\
\hline
\end{tabular}

Almost all (289) patients were treated with Inj. Ceftraixone after positive Widal reports. Out of them 227(77.73\%) responded to the drug. In 62(21.23\%) patients, oral Azithromycin was added after $6^{\text {th }}$ or $7^{\text {th }}$ day. Other drug Cefaperazone was used in 2 patients and 1 patient was treated with Inj.Amoxiclav. Almost all patients were discharged on Oral Cefixime after 24 hours of afebrile stay at hospital.

Table 6: Duration of Hospitalization

\begin{tabular}{|c|c|c|}
\hline Duration of hospitalization & No of patients & \% \\
\hline$<3$ days & 52 & $17.80 \%$ \\
\hline $3-6$ days & 70 & $23.97 \%$ \\
\hline $6-9$ days & 158 & $54.10 \%$ \\
\hline$>9$ days & 12 & $4.10 \%$ \\
\hline
\end{tabular}


$52(17.80 \%)$ patients were discharged within 3 days; 70(23.97\%) patients were discharged before 6 days while $158(54.10 \%)$ patients required hospital stay of 6-9 days. Only 12 patients $(4.10 \%)$ had to remain admitted for more than 9 days. There was no mortality in our study. Serious complications like intestinal perforation, peritonitis and Myocarditis were also not observed in our study.

\section{Discussion}

In our study we noted $6.16 \%$ cases below 2 years of age and $18.49 \%$ were between 2 to 5 years of age. $42.46 \%$ were between 5 to 10 years and $32.87 \%$ pediatric patients were above 10 years of age. Ramaswamy et al noted $1.8 \%$ cases in less than 1 year, $16 \%$ between 1 to 2 years, $32 \%$ between 2 to 5 years, $33.5 \%$ between 5 to 10 years and $15.8 \%$ in more than 10 year children [5].

Among the cases $(6.16 \%)$ below 2 years; $11.11 \%$ were between 6 months to 12 months and remaining $88.88 \%$ were between 1 to 2 years. No case was reported below 6 months of age. Monorama et al noted $10.9 \%$ of total cases below 2 years of which majority $(85.7 \%)$ were between 13 to 20 months of age and only $14.3 \%$ cases were seen in infancy all of whom were more than 6 months of age [ 6]. Saha et al stated in their study that according to recent reports infants and children below 2 years of age are highly susceptible to typhoid fever [ 7 ].

The preschool children have 8-9 times more risk for S.typhi infection than older persons in highly disease endemic areas [9]. Our data indicate high incidence of typhoid fever in children below 5 years $(24.65 \%)$. This suggests that our area has high incidence of typhoid fever. This findings are consistent with earlier work of Sinha A et al showing that in high incidence area, the incidence of typhoid fever in preschool children can approximate that of school age children [10].

The high disease burden in pre school children in our area highlights the importance of vaccine at early age as well as improvement in water sanitation and hygiene [4].

$52.05 \%$ were males and $47.94 \%$ cases were females making ratio of 1.08:1. Ramaswamy et al noted M: F ratio of 1.29:1 in his study [5].

We noted fever as a main presenting complaint in all cases. Other common symptoms were vomiting (49.31\%), diarrhea (36.98\%), and cough (33.56\%). Altered sensorium (2.73\%) and convulsion (2.05\%) were rarely associated symptoms. Ramaswamy et al noted fever in all cases and vomiting in $49 \%$ and diarrhea in $29 \%$ cases as associated symptoms [5]. S.
Jog et al noted vomiting, abdominal pain and loose stool as most common associated symptoms in $42 \%$, $33.6 \%$ and $31 \%$ patients respectively [11]. We noted only Hepatomegaly in $51.36 \%$, only Splenomegaly in $14.72 \%$ and hepatosplenomegaly in $20.54 \%$ patients. Ramaswamy et al noted Hepatomegaly in $71 \%$ and Splenomegaly in 34\% [5] while S Jog et al noted only Hepatomegaly in $15.9 \%$ only Splenomegaly in $7.5 \%$ and hepatosplenomegaly in $12.6 \%$ cases [5].

We used widal test for diagnosis of typhoid fever as it is cost effective, easily available, rapid diagnostic test. Blood culture is the gold standard for diagnosis of typhoid in $1^{\text {st }}$ week of illness but it was not possible in all cases because most patients were admitted after 1 week of fever as well as cost factor was the major hurdle. Stool cultures were done in only 3 patients who needed to be admitted for more than 14 days and were having complained of persistent diarrhea.

$77.73 \%$ patients of typhoid fever became afebrile within 6 to 7 days of Inj. Ceftraixone. In only $21.23 \%$ cases it was required to add Oral Azithromycin along with Inj. Ceftraixone to treat typhoid fever. S Jog et al also noted that $62.1 \%$ patients of typhoid fever were treated by only Inj. Ceftraixone and combination of Inj. Ceftraixone and Azithromycin was used in $13.4 \%$ cases [11].

In our studies $58.20 \%$ patients required more than 6 days hospital stay while remaining $41.80 \%$ cases were discharged within 6 days. Ramaswamy et al noted mean hospital stay of 6.5 days in their study for typhoid fever [5].

\section{Conclusion}

The incidence of typhoid fever was $5.63 \%$ amongst the total admitted patients. High morbidity was observed but with availability of third generation cephalosporin, mortality has reduced which was $0 \%$ in our study. $6.16 \%$ patients were below 2 years of age which shows changing trends in age of presentation which was considered rare below 5 years of age [12]. With availability of conjugated vaccine against typhoid fever, we can prevent it in young children. 
Funding: None

Conflict of Interest: None

Permission from IRB: Yes

\section{References}

1. Amdekar Y K; Typhoid fever. IAP Textbook of Pediatrics $4^{\text {th }}$ Edition $2009: 384-386$.

2. Kothari A, Pruthi A, Chugh TD. The burden of enteric fever. J Infect Dev Ctries. 2008 Aug 30;2(4):253-9.

3. Reller M, Salmonella Species. Principles and Practice of Pediatric Infectious Diseases 3rd Edition 2008: 812816.

4. Ochiai RL, Acosta CJ, Danovaro-Holliday MC, Baiqing D, Bhattacharya SK, Agtini MD, Bhutta ZA, Canh do G, Ali M, Shin S, Wain J, Page AL, Albert MJ, Farrar J, Abu-Elyazeed R, Pang T, Galindo CM, von Seidlein L, Clemens JD; Domi Typhoid Study Group. A study of typhoid fever in five Asian countries: disease burden and implications for controls. Bull World Health Organ. 2008 Apr;86(4):260-8.

5. Ganesh R, Janakiraman L, Vasanthi T, Sathiyasekeran M. Mrofile of typhoid fever in children from a tertiary care hospital in Chennai- South India. Indian J Pediatr. 2010 Oct;77(10):1089-92. doi: 10.1007/s12098-010-0196-9. Epub 2010 Sep 30.
6. Verma M, Chhatwal J, Saini V, Singh T. Enteric fever below 2 years of age. Indian Pediatr. 1996 Mar;33(3):229-30.

7. Saha SK, Baqui AH, Hanif M, Darmstadt GL, Ruhulamin M, Nagatake T, Santosham M, Black RE. Typhoid fever in Bangladesh: implications for vaccination policy. Pediatr Infect Dis J. 2001 May;20(5):521-4.

8. Kundu R, Ganguly N, Ghosh TK, Yewale VN, Shah RC, Shah NK; IAP Task Force. IAP Task Force Report: diagnosis of enteric fever in children. Indian Pediatr. 2006 Oct;43(10):875-83.

9. Brooks WA, Hossain A, Goswami D, Nahar K, Alam K, Ahmed N, Naheed A, Nair GB, Luby S, Breiman RF. Bacteremic typhoid fever in children in an urban slum, Bangladesh. Emerg Infect Dis. 2005 Feb;11(2):326-9.

10. Sinha A, Sazawal S, Kumar R, Sood S, Reddaiah VP, Singh B, Rao M, Naficy A, Clemens JD, Bhan MK. Typhoid fever in children aged less than 5 years. Lancet. 1999 Aug 28;354(9180):734-7.

11. Jog S, Soman R, Singhal T, Rodrigues C, Mehta A, Dastur FD. Enteric fever in Mumbai--clinical profile, sensitivity patterns and response to antimicrobials. J Assoc Physicians India. 2008 Apr;56:237-40.

12. Shai Ashkenazi and Thomas G Cleary; Nelson Textbook of Pediatrics $15^{\text {th }}$ edition: 789.

\section{How to cite this article?}

Desai P, Vijapura A.Y. Profile of typhoid fever in admitted pediatric patients from tertiary care hospital. Pediatr Rev: Int J Pediatr Res 2015;2(4):47-51.doi:10.17511/ijpr.2015.i04.03 